\title{
Characteristics of the catalogue according to the KNET network (Northern Tian Shan)
}

\author{
Naylya Sycheva*, Vladimir Sychev \\ Science Research Station of the RAS in Bishkek city, Kyrgyzstan
}

\begin{abstract}
Various characteristics of the catalogue obtained from the data of the KNET network, containing the parameters of more than 10,000 earthquakes that occurred from 1994 to 2020, are considered. A statistical analysis of the number of $P$ - and $S$-waves registered by each station of the network is carried out. The activity of the stations during the localization of earthquakes has been determined. The most active station is AAK. The minimum number of $\mathrm{P}-$ and $\mathrm{S}$-waves is recorded at the ULHL station. Statistical analysis of localization errors has been performed. The boundaries of the territory for which the minimum values of errors are observed are determined. The statistical characteristics of earthquakes in terms of magnitude, time, depth are presented. The distribution of the number of earthquakes by different energy classes in time and the spatial distribution of earthquakes by depths: $0-5 \mathrm{~km}, 5-10 \mathrm{~km}, 10-15 \mathrm{~km}$ and more than $15 \mathrm{~km}$ are constructed. The Gutenberg - Richter law was used to describe the energy distribution function of earthquakes. A representative sample of the catalogue was determined, which includes events with $\mathrm{M} \geq$ 1.8. The b-value for the directory is 0.88 .
\end{abstract}

\section{Introduction}

In 1991, a seismological network KNET was installed on the territory of the Bishkek geodynamic proving ground (BGPG, Northern Tien Shan), which includes 10 digital broadband stations, each of which is equipped with an STS-2 seismological sensor (Fig. 1, triangles). Various aspects of the operation of this network are described in more detail in [1]. The BGPG refers to the territory (see Fig. 1, indicated by the dashed line), which lies within the central segment of the North Tien Shan seismogenic zone and represents the junction zone of the Tien Shan orogen and the Turan plate. The main tectonic structures of the study area at the neotectonic stage are the Kyrgyz meganticline (Kyrgyz ridge) and the Chuya depression located to the north. To the south of the Kyrgyz ridge are the Suusamyr, Kochkor and Jumgal depressions, separated by small ridges. To the west are the Talas, Bolshoi and Maly Karatau ridges, and to the east - the Kungei-Alatau and Terskey-Alatau ridges with the Issyk-Kul intermountain depression separating them.

The stations of the KNET network make it possible to register earthquakes that occurred in the territory of the Northern and Central Tien Shan. To date, the catalogue of earthquakes according to the KNET network data (hereinafter referred to as the catalogue of

* Corresponding author: ivtran@mail.ru 
earthquakes) contains the parameters of more than 10,000 events that occurred from 1994 to 2020 in the indicated territory. The stations of the network being on the territory of the BGPG maximally register weak earthquakes occurring here. Epicenters of earthquakes from the catalogue are shown in Fig. 1.

The processing of KNET data at the Research Station RAS (RS RAS) began in 1995, and it took time to gain experience in the localization of earthquakes, which affected the quality of the catalogue data for 1994-1995, but they can be taken into account when constructing maps of the epicentral location of earthquakes. The highest quality data in the earthquake catalogue have been presented since 1996, which can be used to solve various seismological problems. Since the start of the network in real time (July 1998), the network efficiency has reached $98-99 \%$ (data loss is $1-2 \%$ ). Waveforms with a frequency of $100 \mathrm{~Hz}$ have been stored on the RS RAS since 1999, before this period digital records (with a frequency of $40 \mathrm{~Hz}$ ) can be obtained from the IRIS website (Incorporated Research Institutions for Seismology).

The purpose of this work is to evaluate various characteristics of the earthquake catalogue.

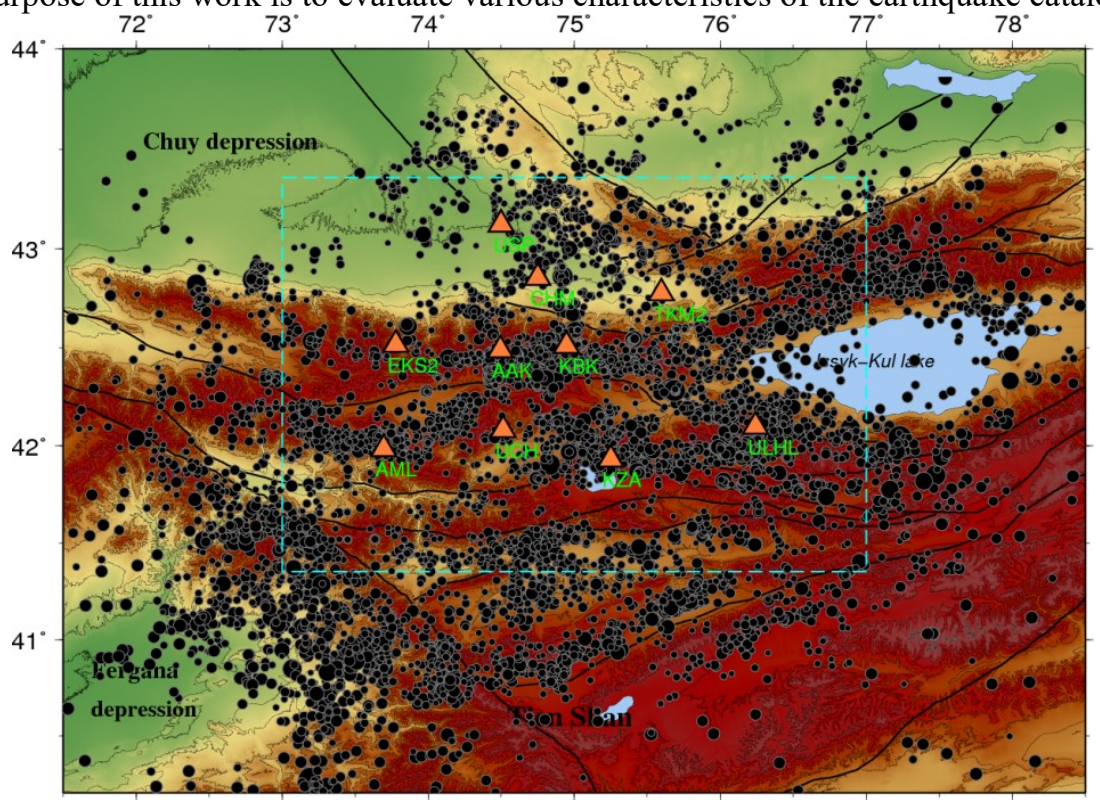

Fig. 1. Epicenters of earthquakes from the catalogue according to the data of the KNET network for 1994-2020 (10604 events). $\Delta$ - Stations position of the KNET network. A rectangle indicates the territory of the BGPG.

\section{Methodology}

Construction of a repeatability graph and the Gutenberg-Richter law. The GutenbergRichter Law [2] expresses the relationship between the magnitude and the total number of earthquakes in any given area and in a certain time period. This law is described by a linear function of the form:

$$
\lg N(M)=a-b M
$$

where $N(M)$ is the number of earthquakes with magnitudes (or classes) not less than $M, a$ and $b$ are constants of the equation. Parameter $a$ ( $a$-value) formally describes seismic activity at $M=0$, and $b$ ( $b$-value) is the angular coefficient of the linear part of the frequency distribution graph of earthquakes, which determines the rate of reduction of the relative number of events with an increase in their magnitude. 
To construct the Gutenberg-Richter distribution, the function $N(M)$ is calculated. The graph of this function is plotted on a logarithmic scale on the axis of the number of earthquakes $\lg N$. Then it is determined $M_{\mathrm{c}}-$ Magnitude of completeness, $M_{\max }$ is the maximum magnitude for which enough events have occurred for statistics over the studied period of time. Then the portion $\left(M_{\mathrm{c}}<x<M_{\max }\right)$ of the $y=\lg N(x)$ function is approximated by the $y=a-b \cdot x$ function.

In terms of the number of events with magnitude $M$ exceeding a certain threshold value $m$ (cumulative distribution), the law of distribution of earthquakes by energies takes the form:

$$
N(M>m) \sim 10^{-\mathrm{bm}}
$$

where $N$ - denotes the number of events for a specified fixed time period and in a given geographical region, $b$ - a constant ( $b$-value), in most cases takes a value of about 0.9 [3].

Representative part of the earthquake catalogue. To correctly determine the representative part of the earthquake catalogue, the approach described in work [4] was used, which involves removing aftershocks from the catalogue before finding the representative part. The authors of this method are Molchan G.M., Dmitrieva O.E. and Smirnov V.B. A set of programs of the same authors was used to remove afteshocks [5].

\section{Results}

Program and Velocity Model. To calculate the parameters of the earthquake hypocenter recorded by the KNET seismological network, the Hypocenter program [6] is used, which uses a six-layer velocity model of the earth's crust calculated by Steve Recker [7]. The study of the velocity models of the Tien Shan region and the choice of the optimal model for calculating the parameters of the earthquake hypocenter were carried out in [8].

The program uses the arrival-file as an input file, where the times of arrival of $P$ - and $S$ waves at the network station are indicated. An example of a seismogram (displacement velocity) of an earthquake $(02 / 10 / 2016, K=10.1)$ with a time stamp of the arrival of $P$ - and $S$-waves is shown in Fig. 2.

a

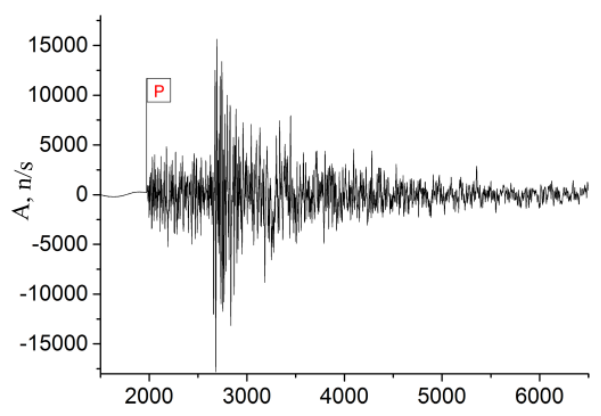

$b$

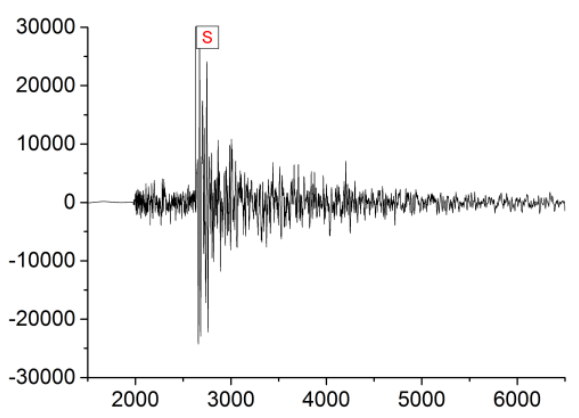

Fig. 2. An example of a recording of the earthquake on $02.10 .2016(K=10.1)$ at the AAK station: $a$ $\mathrm{Z}$ component; $b$ - E component. Flags - time stamps of volume waves arrival at the station.

It was noted above that the earthquake catalogue includes 10604 earthquakes. Each earthquake has a corresponding file of wave arrival times at the station. At present, there are 9717 arrival-files (files for 1995, as well as for individual earthquakes for 2011-2012 are lost).

The number of registered $\boldsymbol{P}$ - and $S$-waves. The statistical analysis of the number of $P$ and $S$-waves for each station of the network is presented in table. 1 . The obtained quantitative data are presented in a sorted form, which makes it possible to assess the contribution of each station of the network in the process of localizing earthquakes. 
Table 1. The number of $P$ - and $S$-waves registered by the stations of the KNET network during the study period in sorted form (1994-2020).

\begin{tabular}{|l|l|l|l|l|l|l|l|l|l|}
\hline \multicolumn{1}{|c|}{$\boldsymbol{P}$-wave } \\
\hline KBK & AAK & USP & TKM2 & UCH & CHM & EKS2 & AML & KZA & ULHL \\
\hline 8451 & 8236 & 7971 & 7676 & 7342 & 7146 & 6391 & 5872 & 5800 & 5538 \\
\hline \multicolumn{8}{|c|}{$\boldsymbol{S}$-wave } \\
\hline AAK & KZA & KBK & CHM & UCH & USP & TKM2 & AML & EKS2 & ULHL \\
\hline 7537 & 7342 & 7314 & 6296 & 6249 & 6131 & 5800 & 4781 & 4338 & 4054 \\
\hline \multicolumn{8}{|c|}{$(\boldsymbol{P}+\boldsymbol{S})$ waves } \\
\hline AAK & KBK & USP & UCH & TKM2 & CHM & KZA & EKS2 & AML & ULHL \\
\hline 15773 & 15765 & 14102 & 13591 & 13476 & 13442 & 13142 & 10729 & 10653 & 9592 \\
\hline
\end{tabular}

The maximum number of $P$-waves was recorded at KBK, AAK and USP stations, the minimum - at ULHL, KZA and AML stations. The maximum number of $S$-waves is at stations AAK, KZA and KBK, the minimum is at stations ULHL, EKS2 and KZA. In terms of the sum $(P+S)$ waves, the maximum number was recorded at the AAK, KBK and USP stations, the minimum - at the ULHL, AML, EKS2 stations. Stations AAK and KBK are located in the central part of the network and allow maximum registration of events that occurred in the territory controlled by the KNET network. The USP station is the extreme northern station, but the data for this station, as the results show (see Table 1.), are actively used for localization. The AML and EKS stations are located in the extreme western part, and the ULHL station is in the extreme eastern part of the network, which limits the registration of events occurring in the extreme opposite areas. Note that the AAK station is located in an adit (quiet station), and the ULHL station is located on the southwestern coast of Lake Issyk-Kul (the impact of waves on the coastlines on the noise level is possible). It is likely that the noise level at these stations also affected the result presented in Table. 1.

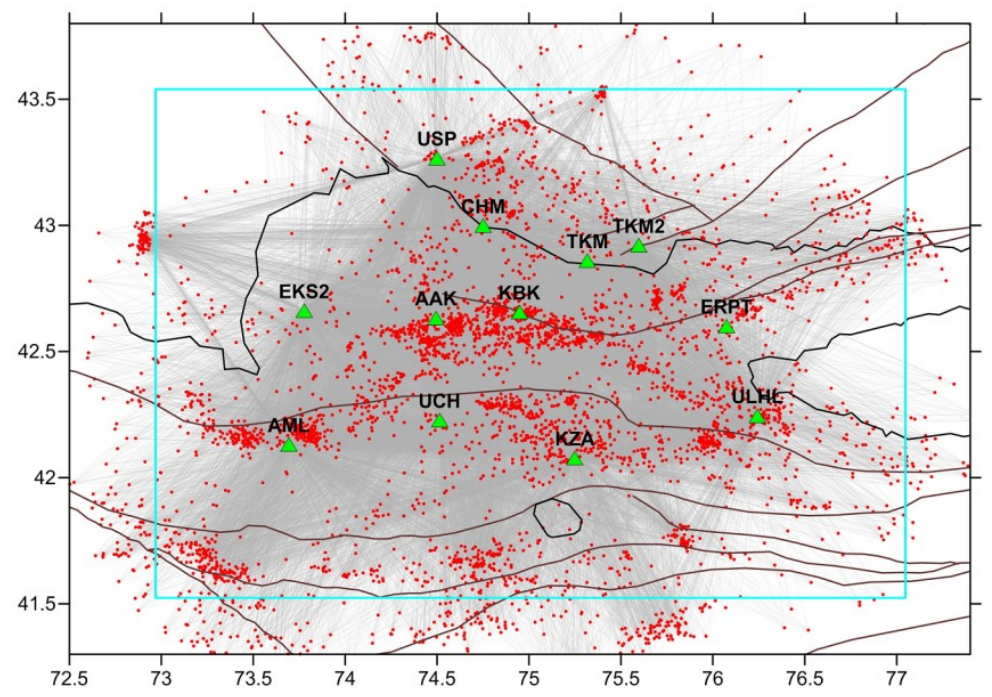

Fig. 3. Seismic wave traces (according to [9]). $\Delta$ is the position of seismic stations in the KNET network. Dots are earthquakes, brown lines are regional faults, black line is the northern border of Kyrgyzstan. The turquoise rectangle marks the territory of the BGPG. 
In fig. 3, as an example, the epicentral position of earthquakes and seismic stations of the KNET network, as well as the $P$-wave traces, which were used in [9] when constructing the attenuation field of seismic waves and seismic tomography, is presented. The territory of the BGPG is covered with a good density of $P$-wave paths.

In total, during the study period, 130265 times of arrival of $P$ and $S$-waves were received on the network stations: 70423 on the $P$-wave and 59842 on the $S$-wave. The arrival times of seismic waves can be used in solving various seismological problems: calculation of station spectra of earthquakes, seismic noise; during seismic tomography, when calculating the attenuation field, quality factor, etc. However, these data are not enough to study deeper layers of the earth's crust, since local earthquakes occur to depths of $30 \mathrm{~km}$. In this case, it is necessary to attract additional data from distant earthquakes.

Errors in calculating earthquake hypocenters. When calculating the hypocenter parameters (latitude, longitude, depth), the Hypocenter program generates three types of calculation errors - the residuals of the seismic wave arrival times at the station (RMS), the horizontal error (ERH, epicentral position) and the vertical error (ERZ, depth). The estimation of the number of earthquakes is carried out, the parameters of which are determined with a given level of error. Table 2 shows the ranges of the considered errors (RMS, ERH, ERZ) and the corresponding number of earthquakes. For $50 \%$ of earthquakes, RMS is less than $0.3 \mathrm{~s}$, and for $\sim 90 \%$ of events does not exceed $0.5 \mathrm{~s}$, which corresponds to an error in determining the coordinates of hypocenters up to $3000 \mathrm{~m}$. The horizontal error (ERH) for $83 \%$ of earthquakes is less than $3 \mathrm{~km}$, and in depth ( ERZ) for $86 \%$ of events is less than $5 \mathrm{~km}$.

Table 2. Error ranges, number of earthquakes and percentage. Period under review (1996-2020 гг.).

\begin{tabular}{|c|c|c|c|c|c|c|}
\hline \multicolumn{7}{|c|}{ RMS, $\mathbf{s}$} \\
\hline $\mathbf{0 - 0 . 1}$ & $\mathbf{0 . 1 - 0 . 2}$ & $\mathbf{0 . 2 - 0 . 3}$ & $\mathbf{0 . 3 - 0 . 5}$ & $\mathbf{0 . 5}-\mathbf{1 . 0}$ & $>\mathbf{1}$ & \\
\hline 150 & 1592 & 3389 & 3696 & 975 & 19 & \\
\hline $1.52 \%$ & $16.21 \%$ & $34.5 \%$ & $37.63 \%$ & $9.92 \%$ & $0.19 \%$ & \\
\hline \multicolumn{7}{|c|}{ ERH, km } \\
\hline $\mathbf{0 - 0 . 5}$ & $\mathbf{0 . 5 - 1}$ & $\mathbf{1 - 2}$ & $\mathbf{2 - 3}$ & $\mathbf{3 - 5}$ & $\mathbf{5 - 1 0}$ & $>\mathbf{1 0}$ \\
\hline 1322 & 2863 & 2681 & 1347 & 1019 & 518 & 0.72 \\
\hline $13.46 \%$ & $29.15 \%$ & $27.29 \%$ & $13.3 \%$ & $13.71 \%$ & $5.2 \%$ & $2.74 \%$ \\
\hline \multicolumn{7}{|c|}{ ERZ, km } \\
\hline $\mathbf{0 - 1}$ & $\mathbf{1 - 2}$ & $\mathbf{2 - 3}$ & $\mathbf{3 - 5}$ & $\mathbf{5 - 1 0}$ & $>\mathbf{1 0}$ & \\
\hline 1908 & 3312 & 1585 & 1647 & 1057 & 312 & \\
\hline $19.42 \%$ & $33.72 \%$ & $16.13 \%$ & $16.77 \%$ & $10.76 \%$ & $3.17 \%$ & \\
\hline
\end{tabular}

In fig. 4 shows the epicentral position of earthquakes that occurred in 1996-2020. and against their background, the epicentral position of events with a level of RMS $\leq 0.3 \mathrm{~s}$ is marked in inverse color (Fig. 4a); ERH $\leq 2.5 \mathrm{~km}$ (Fig.4b); ERZ $\leq 2 \mathrm{~km}$ (Fig.4c). The main part of the events, the position of which is marked in inverse colors, is located on the territory of the BGPG, which is marked on the maps with a turquoise rectangle.

Table 3. Boundary values of the catalogue parameters according to the KNET network data.

\begin{tabular}{|l|c|c|c|c|c|c|c|c|c|}
\hline Parameters & Date & $\boldsymbol{\varphi},{ }^{\circ} \mathbf{n} . \mathbf{l}$. & $\boldsymbol{\lambda},{ }^{\circ} \mathbf{e} . \mathbf{l}$. & $\begin{array}{c}\boldsymbol{H}, \\
\mathbf{k m}\end{array}$ & $\boldsymbol{K}$ & $\boldsymbol{N o}$ & $\begin{array}{c}\text { RMS, } \\
\mathbf{s}\end{array}$ & $\begin{array}{c}\text { ERH, } \\
\mathbf{k m}\end{array}$ & $\begin{array}{c}\text { ERZ, } \\
\mathbf{k m}\end{array}$ \\
\hline Min & 06.01 .1994 & 37.35 & 68.67 & 0 & 4.77 & 3 & 0 & 0 & 0 \\
\hline Max & 31.12 .2020 & 45.77 & 82.24 & 465 & 14.83 & 20 & 9.78 & 141.3 & 99.9 \\
\hline
\end{tabular}

Note. $\varphi$ - latitude; $\lambda$ - longitude; $H$ - depth; $K$ - class; No- number of components; RMS - residuals of the seismic wave arrival times at the station; ERH - horizontal error; ERZ - vertical error. 
Table 3 shows the boundary values of all parameters of the catalogue. Events for which any RMS, ERH or ERZ parameter exceeds the allowed values are included in the catalogue, and a note to this event indicates that the error for some parameter has an invalid value. The maximum depth of events indicated in the table $(465 \mathrm{~km})$ and the maximum error in its determination $(99 \mathrm{~km})$ indicate the presence of individual such events in the catalogue. According to [10], events in the study area can occur up to a depth of $30 \mathrm{~km}$.
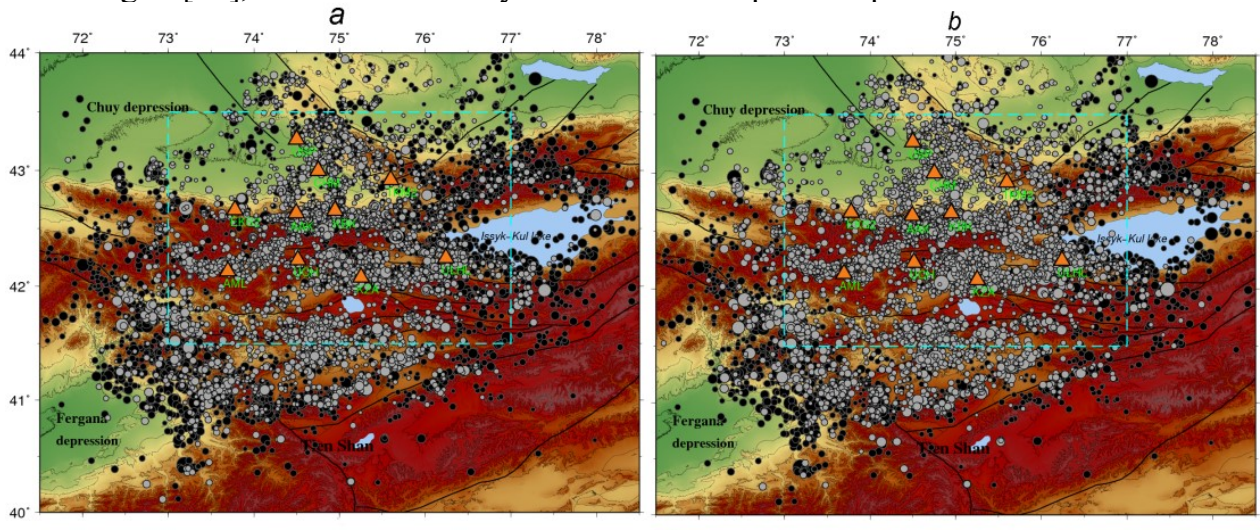

$c$

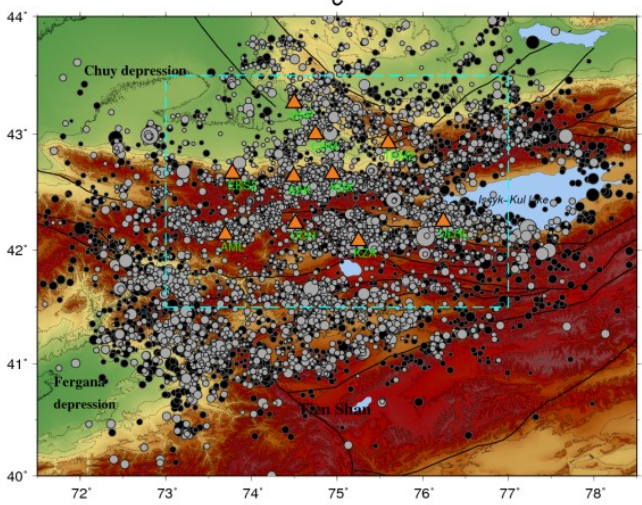

Fig. 4. Epicentral location of earthquakes with RMS $\leq 0.5 \mathrm{~s}(a), \mathrm{ERH} \leq 1.5 \mathrm{~km}(b)$, and ERZ $\leq 2 \mathrm{~km}$ (c). The turquoise rectangle marks the territory of the BGPG.

In [11], a comparison was made of the parameters of earthquake hypocenters from the catalogue obtained from the data of the KNET network (RS RAS) with the catalogue of the Institute of Seismology of the National Academy of Sciences of the Kyrgyz Republic (KIS). We selected 970 local events that took place in the Central Tien Shan in 1996-2001. The comparison was carried out for three parameters of earthquakes: latitude, longitude and class. It was determined that the average value of the difference in latitude coordinates is $2 \mathrm{~km}$, in longitude $\sim 200 \mathrm{~m}$ and in energy class $\sim 0.09$. The noted discrepancies in the parameters under study can be due to the following reasons: different velocity models of the environment used in the CIS and RS RAS, different programs for calculating hypocenters and the handler skill. Insignificant discrepancies in the specified parameters make it possible to consider the catalogue obtained at the RS RAS on the basis of the KNET seismological network as a conditional one.

Statistical characteristics of the catalogue. Some quantitative estimates of the catalogue parameters are shown in Fig. 5. Events in time are distributed unevenly, the most seismically active are 1996, 1999, and 2017 (see Fig. 5b). The main part of the catalogue is made up of weak events $K=6-8$ (see Fig. 5a), which occurred at a depth of $0-15 \mathrm{~km}$ (see 
Fig. 5c). Most of the events are determined by 12-16 components (the total number of registered $P$ and $S$-waves), the maximum possible number of components for a given network configuration can be equal to 20 (10 stations, $P$ and $S$-waves) (Fig.5d).
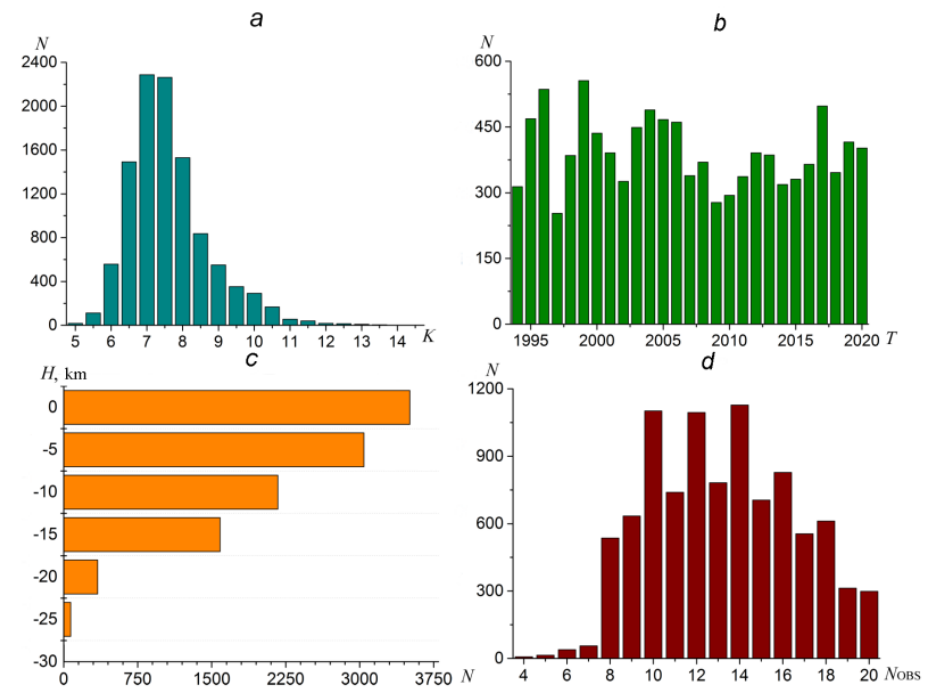

Fig. 5. Histograms of some characteristics of the KNET catalogue (1994-2020): $a$ - class; $b$ - time; $c$ depth; $d$ - the number of phases ( $P$ - and $S$-waves).

Quantitative distribution of earthquakes by energy classes. Above, in Fig. $5 \mathrm{~b}$, the distribution of the number of earthquakes by years is presented, according to which the most seismically active years can be noted. Similar distributions were constructed for separate samples of events that occurred during the network operation in real time (19992020) and formed depending on the earthquake class (Fig. 6).

The most active year for weak events is 1999 (see Fig. $6,6 \leq K<7$ ), where their number exceeds 200 earthquakes. In other years, their value varies from 30 to 90 earthquakes per year. For weak events with $7 \leq K<8$, the maximum number occurs on the period 20032006. (more than 200 earthquakes per year). In other years, their number varies from 150 to 200. For events with $8 \leq K<9$ and $9 \leq K<10$, the histograms have a similar distribution pattern. There are two periods when the level of these events falls to the minimum value 2008-2011 and 2013-2014. The maximum number of earthquakes in the considered samples occurred in 2017. The maximum number of earthquakes with $10 \leq K<11$ occurred in 2006 ( 24 events) and 2017. ( 25 events), the minimum in 2010 (less than 5 events). On average, earthquakes from $11 \leq K<12$ occur 2-6 times a year. The maximum number of such events occured in 2003 ( 9 events) and 2020 (14 events). The maximum number of earthquakes from $12 \leq K<13$ occurred in 2005 and 2007. (5 events each). In some years, earthquakes of this class do not occur, and in other years their number varies within 1-2 earthquakes per year. Less often, events occur with $13 \leq K<14$. In 2004 and 2015, there were 2 earthquakes each, and in the period from 2006 to 2009, there was one earthquake each. In the considered distributions, there is no positive or negative trend in the change in the number of events with a given energy characteristic.

Depth distribution of seismicity. In fig. $5 c$ shows a histogram of the distribution of earthquakes by depth, and Fig. 7 shows their areal distribution at the same depths as on the histogram; earthquakes located below $15 \mathrm{~km}$ were considered in one sample. 


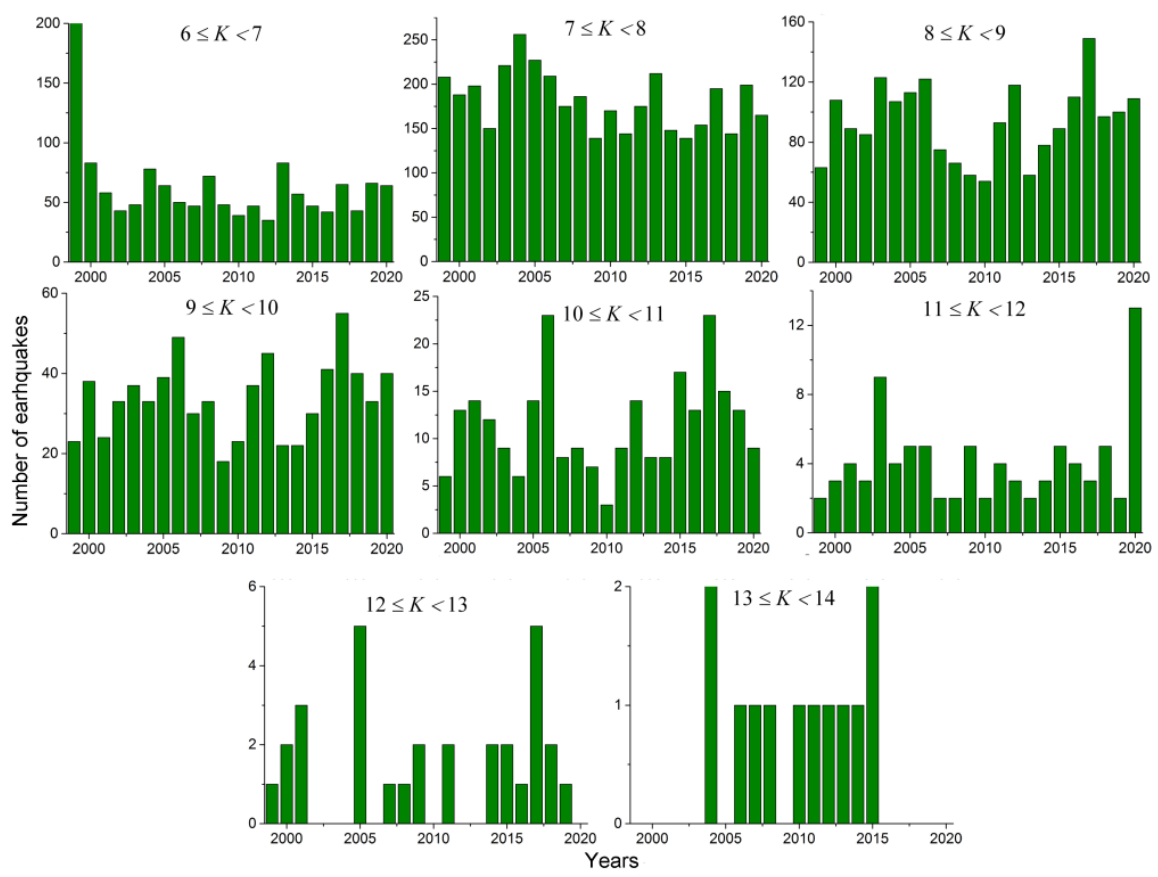

Fig. 6. Distribution of the number of earthquakes by years for the samples formed depending on the class of the earthquake (shown in the graphs). The period under review is 1999-2020.
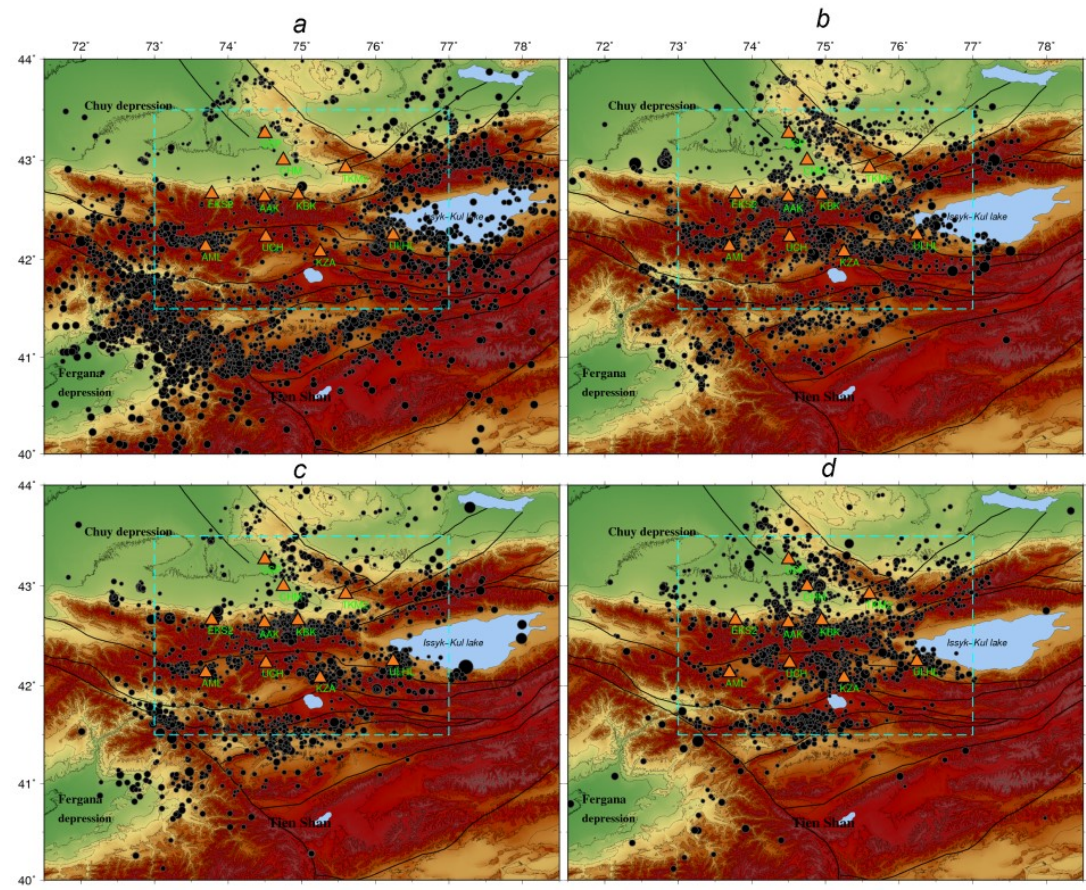

Fig. 7. Epicentral location of earthquakes from the catalogue according to the KNET network data at different depths: $a-0-5 \mathrm{~km}$ (3613 events); $b-5-10 \mathrm{~km}(2960) ; c-10-15 \mathrm{~km}(2167) ; d$ - more than 15 $\mathrm{km}(1865)$. The triangles indicate the stations of the KNET network. 
At a depth of $0-5 \mathrm{~km}$ (see Fig. 7a), most of the events are located outside the KNET stations and are located along the sides of the Issyk-Kul depression and Talas-Fergana fault. A small number of events were noted on the territory of the location of the stations of the KNET network. This configuration of near-surface seismicity is most likely associated with artifacts of the computational process. For depths of 5-10 (see Fig. 7b) and 10-15 km (see Fig. 7c), the seismicity distribution pattern, which is mainly concentrated within the network and along its margins, changes little, apart from the density of events. At a depth of more than $15 \mathrm{~km}$, most of the events are located on the territory bounded by the coordinates of the network edge stations (North Tien Shan self-generating zone), along the Chu-Ili mountains (see Fig.7d) and on the Moldo Too ridge. According to the results obtained, $\sim 50 \%$ of earthquakes fall to depths of $5-15 \mathrm{~km}$.

Representative sample of the earthquake catalogue. After removing aftershocks from the earthquake catalogue, a representative sample of the catalogue was calculated. For the calculation, the class of earthquakes and the magnitude were considered, recalculated from the class according to the well-known expression linking magnitude and energy class [12]: $K=1.8 \cdot M+4$. A representative sample was determined: for the entire catalogue; for a catalogue without aftershocks and a catalogue without aftershocks bounded by BGPG coordinates. To plot the frequency of occurrence, the number of earthquakes that fell within a certain range of magnitudes (classes) was calculated; the step of changing the range was 0.1 . Also, the cumulative Gutenberg - Richter distribution was constructed according to the linear part of which the representative sample and the parameters of the equation describing the approximation of the linear portion of the distribution were determined.

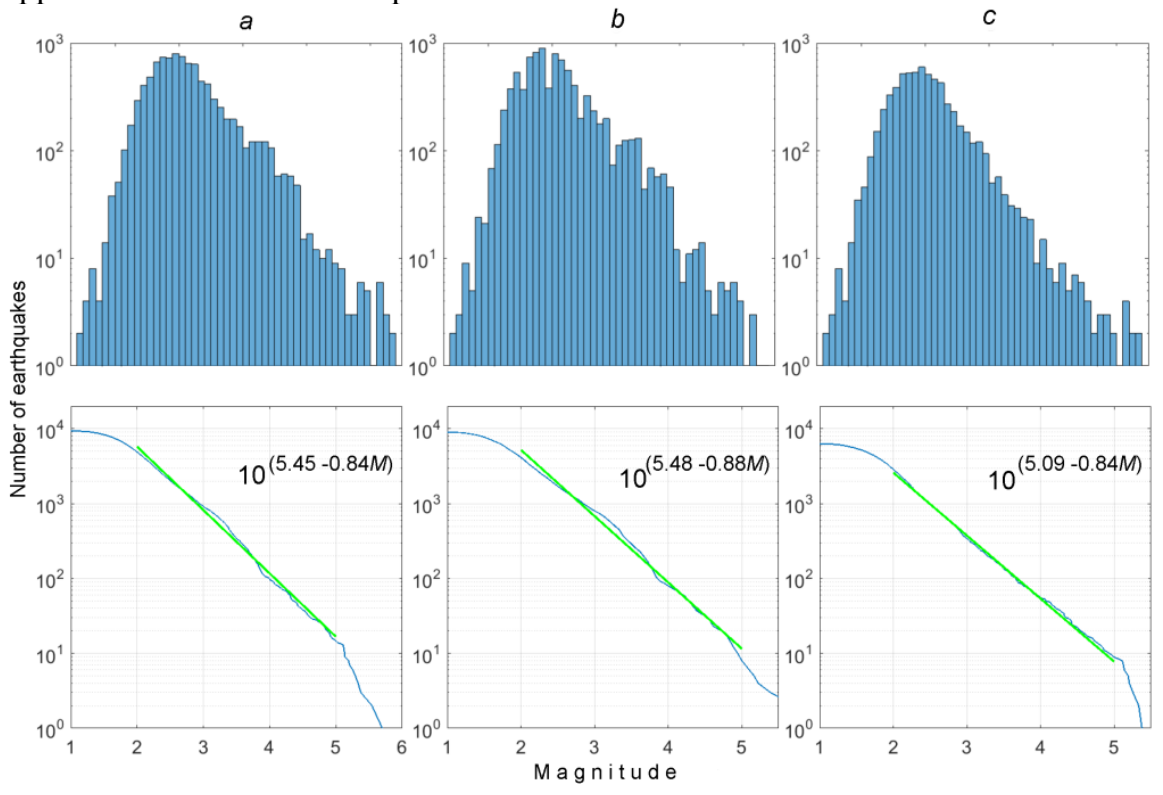

Fig. 8. The repeatability graph and the cumulative Gutenberg - Richter distribution calculated from the magnitude for the complete catalogue using the KNET data $(a)$, for the KNET catalogue after removing the aftershocks $(b)$ and the catalogue that includes earthquakes that occurred in the BGPG territory $(c)$.

In fig. 8 shows the frequency plots (top row) and cumulative Gutenberg - Richter distributions (bottom row) calculated by magnitude, where the equations describing the linear part of the cumulative distribution are also marked. The characteristics of the Gutenberg - Richter distribution obtained for the classes and magnitudes are presented in Table. 4. 
The boundaries of the linear part of the Gutenberg - Richter distribution, presented in table. 4 show that the representative part of the catalogue, limited by the BGPG coordinates, begins with earthquakes with $M \geq 1.7$, and for the complete catalogue, events starting from $M \geq 1.8$ are representative. The seismological network KNET is located inside the territory of the BGPG, and allows full registration of events with $M \geq 1.7$, with distance from the boundaries of the BGPG, the number of registered weak earthquakes decreases. Therefore, when solving some problems on the basis of a catalogue based on the data of the KNET network, it is advisable to restrict ourselves to the territory of the BGPG.

Table 4. List of catalogues, characteristics of the Gutenberg - Richter distribution and the boundaries of the linear part of the distribution (1996-2020)

\begin{tabular}{|c|c|c|c|c|c|c|c|c|}
\hline \multirow{3}{*}{$\begin{array}{c}\text { Catalogue } \\
\text { KNET }\end{array}$} & \multicolumn{4}{|c|}{$\begin{array}{l}\text { Distribution } \\
\text { parameters }\end{array}$} & \multirow{2}{*}{\multicolumn{4}{|c|}{ Distribution Linear Part }} \\
\hline & \multicolumn{2}{|c|}{$K$} & \multicolumn{2}{|c|}{$M$} & & & & \\
\hline & $a$ & $b$ & $a$ & $b$ & $K_{\min }$ & $K_{\max }$ & $M_{\min }$ & $M_{\max }$ \\
\hline $\mathrm{A}$ & 7.344 & 0.472 & 5.451 & 0.846 & 7.3 & 13.2 & 1.8 & 5.1 \\
\hline B & 7.548 & 0.502 & 5.488 & 0.885 & 7.5 & 12.8 & 1.9 & 4.9 \\
\hline $\mathrm{C}$ & 6.992 & 0.470 & 5.097 & 0.841 & 7.0 & 13.2 & 1.7 & 5.1 \\
\hline
\end{tabular}

Note. A - earthquake catalogue, B - earthquake catalogue without aftershocks, C - catalogue of earthquakes without aftershocks, limited by BGPG coordinates.

The parameters of the linear part of the Gutenberg - Richter distribution - $a$-value and $b$ value - refer to the most important quantitative characteristics of the seismic regime. The slope of the graph expresses the ratio between the number of strong and weak seismic events, or (already in physical interpretation) the ratio between the number of large and small fractures in the geological environment. The graph level characterizes seismic activity - the total intensity of seismic manifestations in the considered seismically active area. These parameters form the basis of the quantitative seismic zoning method. In [3], it is indicated that for seismically active regions, in most cases, the $b$-value inclination angle takes on a value of 0.9 . For the catalogue according to the KNET network, this parameter has a value of 0.84 ; after removing aftershocks (weak events), its value changes to 0.88 . The $b$-value can be used to assess the geodynamic processes of the seismically active zone.

\section{Conclusion}

The Kyrgyz seismological network KNET, established in 1991, allows registering earthquakes occurring in the territory of the Northern and Central Tien Shan. During the operation of the network, more than 10,000 earthquakes were registered, which occurred from 1994 to 2020. A statistical analysis of various parameters of the catalogue obtained from the data of the KNET network has been carried out. For $50 \%$ of earthquakes in the catalogue, the discrepancy in determining the arrival times of $P$ - and $S$-wave fronts (RMS) is less than $0.3 \mathrm{~s}$, and for $86 \%$ of events it does not exceed $0.5 \mathrm{~s}$. The horizontal error (ERH) for $80 \%$ of events is less than $3 \mathrm{~km}$, and for $83.8 \%$ of events, the error in depth (ERZ) is less than $5 \mathrm{~km}$. In total, 130,265 times of arrival of $P$ - and $S$-waves were recorded during the study period: 70423 along the $P$-wave and 59842 along the $\mathrm{S}$-wave, which can be used to solve various seismological problems. The quantitative temporal distributions of earthquakes, depending on the class of the event, showed that there is no positive or negative trend in the change in the number of events with a given energy characteristic. The distribution of earthquakes by depths: $0-5 \mathrm{~km}, 5-10 \mathrm{~km}, 10-15 \mathrm{~km}$ and more than $15 \mathrm{~km}$ showed that the most reliable depths are determined for earthquakes with a depth of more than $5 \mathrm{~km}$. After removing aftershocks, a representative sample of the catalogue was 
determined. The catalogue is most fully represented by earthquakes with $M \geq 1.8$. The catalogue, limited by the BGPG coordinates, expands this sample with weaker events with $M \geq 1.7$. The slope of the Gutenberg - Richter distribution calculated from the catalogue is 0.88 . The results obtained in the work showed that the catalogue based on the KNET data is most efficiently used for the territory of the Bishkek geodynamic proving ground.

\section{Acknowledgements}

The research was partially carried out within the framework of the state assignment of Research Station of the Russian Academy of Sciences in Bishkek city (topics № AAAA-A19-119020190064-9 and № AAAA-A19-119020190066-3).

\section{References}

1. N.A. Sycheva, L.M Bogomolov., S.I. Kuzikov Computational technologies in seismological research (on the example of KNET, Northern Tian Shan) (IMGG FEB RAS, Yuzhno-Sakhalinsk, 2020)

2. B. Gutenberg, C.F. Richter, Bulletin of the Seismological Society of America, 34 (1944)

3. K. Kasahara, Earthquake mechanics (Cambridge Univ. Press, 1981)

4. G.A. Sobolev, A.V. Ponomarev, Earthquake Physics and Precursors (Nauka, Moskow, 2003)

5. G.M. Molchan, O.E. Dmitrieva, Computational seismology, 24 (1991)

6. B.R. Lienert, E. Berg, L.N.F razer, Hypocenter: an earthquake location method using centered, scaled, and adaptively damped least squares, 76, 3 (1986)

7. S.W. Roecker, T.M. Sabitova, L.P. Vinnik, Journal Geophys. Res., 98, B9 (1993)

8. N.A. Sycheva, S.I. Kuzikov, Geophysical Research, 13, 2 (2012)

9. I.V Sychev., I. Koulakov, N.A. Sycheva, A. Koptev, I. Medved, S.E. Khrepy, N. AlArifi, Journal Geophysical Research Solid Earth, 123, 2 (2018)

10. F.N. Yudakhin, Geophysical fields, depth structure and seismicity of Tian Shan (Ilim, Frunze, 1983)

11. N.A. Sycheva Dis.... edging. physical. - a mat. Sciences (Moscow, 2005)

12. Yu.V. Riznichenko, Problemy seysmologii (Nauka, Moscow, 1985) (in Russian) 